\title{
Perinatal outcomes of the antenatally diagnosed omphalocele cases: a single tertiary center experience
}

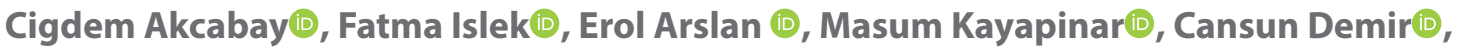 \\ Cuneyt Evruke®, Selim Buyukkurt(1), Mete Sucu®i), Umran Kucukgoz Gulec(i) \\ Department of Obstetrics and Gynecology, Çukurova University, School of Medicine, Adana, Turkey
}

\begin{abstract}
Objectives: To evaluate the perinatal outcomes of antenatally diagnosed omphalocele cases.

Material and methods: This was a retrospective study conducted between July 2014 and February 2020 at the prenatal diagnosis center of a university clinic. Gestational week of diagnosis, associated anomalies, karyotype analysis results, complications during pregnancy, termination/delivery characteristics, and postnatal results were evaluated.

Results: The analysis was performed on 58 patients. The median diagnosis time was 14.5 weeks of gestation. Thirty-three cases (57\%) were defined in the first trimester. 33 (57\%) of 58 patients had one or more concomitant anomalies, while 25 patients (43\%) had isolated omphalocele. The most common associated anomaly was a cardiac anomaly which was observed in 17 fetuses (30\% of all omphalocele cases). Karyotype analysis was performed in forty-five patients (41 in the prenatal period, 4 in the postnatal period). A normal karyotype was detected in 27 cases (60\%). Trisomy 18 was the most common chromosomal anomaly $(n=15,33.3 \%)$. Thirty of 58 patients $(52 \%)$ requested termination of pregnancy (TOP) in the early pregnancy period. Thirteen of the cases died in-utero (22\%). Fifteen pregnancies resulted in live births (26\%), of those eight were lost in the first year of life (six of them had additional anomalies, while two of them had isolated omphalocele but the omphalocele pouch was containing the liver in those two babies).

Conclusions: Most of the cases with an omphalocele can be diagnosed in the first trimester. Cardiac anomalies were the most common associated anomalies, while trisomy 18 is the most common chromosomal anomaly. Thus, earlier and effective counseling can be made about the prognosis of pregnancy.
\end{abstract}

Key words: exomphalos; perinatal outcomes; omphalocele

Ginekologia Polska 2022; 93, 1: 37-41

\section{INTRODUCTION}

Omphalocele (exomphalos) is one of the most common anterior abdominal wall defect and its frequency is reported to be 1 in 4000-7000 live births [1]. It is defined as herniation of intra-abdominal organs covered with peritoneal membrane and umbilical cord due to midline defect of the anterior abdominal wall. The peritoneal membrane consists of the wharton gel between the inner layer of the peritoneum and the outer layer of the amnion [2]. Abdominal wall herniation is considered physiological before the $12^{\text {th }}$ gestational week. For this reason, the diagnosis of omphalocele is made more during the first trimester screening $[3,4]$ especially during the nuchal translucency (NT) measurement as part of first trimester screening [5]. This is the main reason for the high misdiagnosis rates in the first trimester.
Detailed ultrasonographic examination including fetal echocardiography and karyotype analysis should be requested in terms of searching for the concomitant anomalies that have an increased rate in omphalocele cases. The frequency of chromosomal anomalies, especially trisomy 18 , was higher in omphalocele cases. Trisomy 18 is present in $80 \%$ of cases if other anomalies accompanied to omphalocele, whereas the rate is $54 \%$ in the omphalocele cases accompanied with only increased NT [6]. Since omphalocele may be associated by many structural anomalies (Pentalogy of Cantrell, Beckwith-Wiedeman syndrom, bladder exstrophy, imperforate anus, spina bifida complex/OEIS complex, neural tube defects, diaphragmatic herniation, single gene disorders and many other syndromes) tar-

Corresponding author:

Umran Kucukgoz Gulec

Department of Obstetrics and Gynecology, Çukurova University, School of Medicine, 01330 Saricam/ Adana Turkey, phone: 90322 3386060-3195-3196, fax: 90 322 3386527 e-mail: ukucukgoz@yahoo.com 
geting detailed ultrasonography in the second trimester and if necessary cyto-genetic analysis such as comparative genetic hybridization should be performed even if it is thought to be isolated in the first trimester [7]. Cardiac anomalies especially secundum atrial septal defect (ASD) and muscular ventricular septal defect (VSD) are the most common concomitant structural anomalies in omphalocele cases. The most common extracardiac anomalies are in the genitourinary system (Pyelectasis, Hydronephrosis, Cloacal exstrophy, Multicystic kidney) and gastrointestinal system (Beckwith-Wiedeman syndrome). Pulmonary hypoplasia is also common, especially if the defect is large $[8,9]$. Therefore, detailed cardiac evaluation is essential in these cases.

The prognosis of the omphalocele is usually severe in non-isolated cases. Omphalocele sac can include liver, stomach and intestinal. There is a high termination rate and in-utero mortality rate for omphalocele because of the associated structural and chromosomal anomalies. Chromosomal anomaly and/or related structural anomaly incidence rate can be high as $88 \%$ for omphalocele. Therefore, live birth rate is reported to be $25-40 \%[1,10]$. But prognosis is better in isolated omphalocele cases. The most difficult question is to reveal whether the case is really isolated omphalocele.

In this study, we aimed to evaluate the prenatal results of patients with omphalocele diagnosed and followed up in our clinic.

\section{MATERIAL AND METHODS}

This retrospective study was conducted between July 2014 and February 2020 at the Maternal-Fetal Unit of a University Hospital. This study was approved by the Faculty of Medicine Ethics Committee. This center is the tertiary referral center for the perinatal diagnosis. Women admitted for routine ultrasound examination or referred to our hospital for a suspected fetal anomaly underwent detailed fetal anomaly ultrasonography scan. For those detected with omphalocele and continued pregnancy, a detailed ultrasonographic evaluation including fetal cardiography was performed to determine associated anomalies by using VolusonE6 (GE Medical Systems, Zipf, Austria) with a transabdominal 4-8--MHz probe. The data were scanned retrospectively from the viewpoint recording system and the neonatal registry system. Maternal age, gravidity, parity, gestational age at diagnosis, associated structural malformations, whether invasive diagnostic procedures were performed or not, the results of karyotype analysis and fetal echocardiography results were determined. Each patient was evaluated in a council of clinical geneticists, pediatric surgeons and perinatologists. Each family was informed in detail about the current situation by the council. TOP were performed if the family requested the termination and the fetus was evaluated postmortem if the family approved this examination. The ratio of TOP was determined. During the follow-up, whether intrauterine growth restriction (IUGR), intrauterine fetal death, preterm labor were evaluated. IUGR was defined as fetal ultrasonographic measurements being below $10 \%$ percentile according to gestational age. Small gestational age (SGA), IUGR distinction was not made. Doppler studies were evaluated after the diagnosis of IUGR. Delivery before completing the $37^{\text {th }}$ gestational weeks were defined as preterm delivery. Gestational age at delivery, route of delivery, low APGAR score (10th minute $\leq 5$ ), birth weight, size and content of defect and postnatal information were recorded by using the labor unit registry and neonatal intensive care (NICU) registry. Neonatal care was performed by the neonatologist and the pediatric surgery team in same hospital.

Statistically analysis was performed by using SPSS $^{\circ}$ (SPSS Inc., Chicago, IL, USA, version 20). Descriptive analysis was performed for this study. Continuous data was presented as mean $\pm S D$, median (min-max.). Categorical data was presented as $\mathrm{n}(\%)$.

\section{RESULTS}

Seventy-four patients with omphalocele were detected during the study period. Sixteen of them were excluded from the study because follow-up data were not available. Analyzes were performed on 58 cases. Mean maternal age was $29.0 \pm 6.7$, primigravidity was present in 18 (31\%) cases. The median of diagnosis time was 14.5 weeks of gestation. Thirty-three cases (57\%) were defined in the first trimester. Twenty-five cases did not have any associated anomalies (43\%), 33 of total cases (57\%) had one or more associated anomalies. Thirty of 58 cases (52\%) performed termination of pregnancy (TOP) in the early pregnancy period. Thirteen of the cases (22\%) died in-utero. Fifteen pregnancies (26\%) resulted in live births. Clinical and demographic variables and results were presented in Table 1.

The most common associated anomaly is cardiac anomaly and it was observed in 17 fetuses. Among the cardiac anomalies, atrioventricular septal defect (AVSD) was the most common anomaly. Central nervous system (CNS) anomalies were observed in 15 cases. Urogenital system anomalies were the third most common anomalies with eight cases. Other system anomalies most frequently belong to the skeletal system (short femur length and short humerus length) and were seen in six cases. Thirteen cases had multiple anomalies associated omphalocele. Associated anomalies and their properties are shown in Table 2.

Karyotype analysis was performed in 41 cases in the pre-natal period and in four cases in the post-natal period (78\%). Normal karyotype was detected in 27 cases (60\%). Trisomy 18 was the most common karyotype anomaly with 15 cases (83\%). Trisomy 13 was seen in two cases and Turner 
Table 1. Demographic and clinical properties of the cases

Omphalocele $\mathbf{n}=\mathbf{5 8}$

mean \pm SD $n \%$

median (min-max)

\begin{tabular}{|l|l|}
\hline Maternal age & $\begin{array}{l}29.0 \pm 6.7 \\
28(17-44)\end{array}$ \\
\hline Primigravidity & $18(31 \%)$ \\
\hline Twin pregnancy & $4(6.8 \%)$ \\
\hline Gestational week at diagnosis & $\begin{array}{l}15.8 \pm 3.7 \\
14.5(12-25)\end{array}$ \\
\hline First trimester diagnosis & $33(57 \%)$ \\
\hline $\begin{array}{l}\text { Fetal karyotype } \\
\text { N/A }\end{array}$ & $13(22 \%)$ \\
\hline $\begin{array}{l}\text { Normal (n=45) } \\
\text { Abnormal (n=45) }\end{array}$ & $27(60 \%)$ \\
\hline $\begin{array}{l}\text { Associated anomalies } \\
\text { None }\end{array}$ & $18(40 \%)$ \\
\hline Present & $25(43 \%)$ \\
\hline $\begin{array}{l}\text { Pregnancy outcomes } \\
\text { Termination of pregnancy } \\
\text { In-utero exitus } \\
\text { Delivery }\end{array}$ & $33(57 \%)$ \\
\hline
\end{tabular}

SD — standard deviation; N/A - not-available

\begin{tabular}{|c|c|c|}
\hline Associated anomalies & $\begin{array}{l}(\mathrm{n} \%) \text { in total } \\
\text { cases } \\
(\mathbf{n}=\mathbf{5 8})\end{array}$ & $\begin{array}{l}\% \text { in non- } \\
\text { isolated } \\
\text { cases }(n= \\
33)\end{array}$ \\
\hline $\begin{array}{l}\text { Cardiac } \\
\text { AVSD } \\
\text { VSD } \\
\text { Hypoplastic left heart } \\
\text { Hypoplastic left heart double } \\
\text { outlet right ventricle } \\
\text { Fallot Tetralogy }\end{array}$ & $\begin{array}{l}17(29 \%) \\
10 \\
2 \\
2 \\
1 \\
2\end{array}$ & $52 \%$ \\
\hline $\begin{array}{l}\text { CNS } \\
\text { Cerebellar hypoplasia } \\
\text { Holoprosencephaly } \\
\text { Encephalocele } \\
\text { Spina bifida } \\
\text { Acrania } \\
\text { Ventriculomegaly } \\
\text { Mega sisterna magna }\end{array}$ & $\begin{array}{l}15(26 \%) \\
2 \\
3 \\
3 \\
1 \\
2 \\
2 \\
2\end{array}$ & $45 \%$ \\
\hline $\begin{array}{l}\text { Urogenital system } \\
\text { Pyelectasis } \\
\text { Polycystic kidney } \\
\text { Multicystic dysplastic kidney } \\
\text { Increased renal echogenicity }\end{array}$ & $\begin{array}{l}8(14 \%) \\
3 \\
2 \\
2 \\
1\end{array}$ & $24 \%$ \\
\hline $\begin{array}{l}\text { Others } \\
\text { Skeletal system (short FL, } \\
\text { short HL) } \\
\text { Single umbilical artery }\end{array}$ & $\begin{array}{l}6(10 \%) \\
3 \\
3\end{array}$ & $18 \%$ \\
\hline $\begin{array}{l}\text { Multiple anomalies in } \\
\text { different systems }\end{array}$ & $13(22 \%)$ & $39 \%$ \\
\hline Isolated omphalocele & $25(43 \%)$ & \\
\hline
\end{tabular}

AVSD - atrioventricular septal defect; VSD - ventricular septal defect; $\mathrm{FL}$ - femur length; $\mathrm{HL}$ - humerus length

\begin{tabular}{|c|c|}
\hline & $(n=45)$ \\
\hline Normal & $27(60 \%)$ \\
\hline Aneuploidy & $18(40 \%)$ \\
\hline Trisomy 18 & 15 (83\%) \\
\hline Trisomy 13 & $2(11 \%)$ \\
\hline Turner $(45, \mathrm{X} 0)$ & 1 (6\%) \\
\hline
\end{tabular}

Table 4. Pregnancy and delivery outcomes of the omphalocele cases

\begin{tabular}{l|l|}
\hline & $\begin{array}{l}\text { Omphalocele } \mathbf{n}=\mathbf{5 8} \\
\text { mean } \pm \text { SD, median } \\
\text { (min-max.); } \mathbf{n} \%\end{array}$ \\
\hline Preterm delivery & $7 / 15(46 \%)$ \\
\hline IUGR & $7 / 28(25 \%)$ \\
\hline Gestational week at delivery & $34.3 \pm 4.5$ \\
\hline Route of delivery (live) & $36(24-39)$
\end{tabular}

SD - standard deviation; IUGR - intrauterine growth restriction; $\mathrm{C} / \mathrm{S}-$ cesarean section

$(45, \mathrm{X} 0)$ was determined in one case. Results of the karyotype analysis were presented as Table 3.

Preterm delivery was determined in seven cases (46\%). IUGR was determined in seven cases (25\%). Fifteen live births were performed. Mean gestational week at the delivery was 34.3 week. One-third of the cases have been delivered by the vaginal route. Omphalocele alone was not considered a cesarean indication, and the decision for cesarean was determined according to general obstetric indications. $10^{\text {th }}$ minute low APGAR score $(\leq 5)$ was present in the 3 cases. Eight of them were lost in the first year (six of them had additional anomalies, two cases were isolated omphalocele, but liver was also present in the pouch). There were no additional major organ anomalies or karyotype abnormalities of seven babies who were born alive and continued their lives, and the youngest was seven months old and the eldest was three years old. Obstetrics and neonatal outcomes of the cases were presented in the Table 4. 


\section{DISCUSSION}

In our series of 58 cases, we evaluated obstetric and neonatal outcomes in cases with omphalocele. Due to the liberal use of ultrasonography in the antenatal period and increased evaluation experience and knowledge, omphalocele diagnostic accuracy is close to $100 \%$ [1]. In the intrauterine period, the differential diagnosis of omphalocele and gastroschisis can be made almost 100\%. Gastroschisis was not ever misdiagnosed as omphalocele in our series. The sensitivity for omphalocele diagnosis in the first trimester is reported to be $90 \%[10,11]$. In our study, 33 of the 58 cases (57\%) were diagnosed omphalocele correctly in the first trimester. The diagnosis of omphalocele in the first trimester is very important in terms of detecting structural and chromosomal anomalies and enabling earlier decisions about the pregnancy. In omphalocele cases, live birth rates are as low as $25-40 \%$ because elective TOP rates and in-utero exitus rates are high [10]. In our series, the TOP rate was high as $52 \%(n=30)$ and live birth rate was $25 \%(n=15)$. According to a study conducted in 11 countries in Europe, the live birth rate for omphalocele $(n=137)$ was given as $41 \%$, fetal death rate was $22 \%$ and TOP rate was $37 \%$ [12].

The prognosis of omphalocele depends on concomitant structural and/or chromosomal anomalies [1, 2, 6-10]. Structural anomalies were associated in $57 \%$ of our cases while chromosomal anomalies were found in $40 \%$. In another series of 90 cases, $69 \%$ of central omphalocele cases had chromosomal anomaly, while in epigastric omphalocele, this rate was $12 \%$ [13]. They concluded that the types of the omphalocele may be different entities but as a result, $22 \%$ of cases live and omphalocele has poor prognosis irrespective of the types. Thus in a study evaluating 79 isolated omphalocele cases diagnosed in the first trimester and without structural and chromosomal anomalies, live birth rate was $68 \%$ and the mortality rate was $33 \%$ [10]. In another series of 67 cases, the rate of chromosomal anomaly was reported as $39 \%$ like our results [14]. In another study evaluating 98 cases diagnosed in the first trimester, it was found that $45.9 \%$ of the cases were associated by major structural anomalies and $53.8 \%$ had chromosomal anomalies [6]. Fleurke-Rozema $\mathrm{H}$ et al. [15], reported that 141 cases with omphalocele $83 \%$ had additional anomalies of which $57 \%$ had a chromosomal anomaly. Similarly, in the presence of increased NT (> $3.5 \mathrm{~mm}$ ), chromosomal anomaly was detected in $40.8 \%$ of cases with omphalocele [16]. A normal NT is therefore a reassuring sign, but the residual risk of aneuploidy may still be as high as $28 \%$ [17]. In another series, the rate of related structural anomaly was reported as $78.7 \%(26 / 33)$, and the rate of chromosomal anomaly was $27.6 \%$ (8/29) [18]. The most common accompanying chromosomal anomaly is trisomy $18[1,2,8]$. Trisomy 18 was the most common karyotype anomaly $(15 / 18)$ in our series. The most common associated structural anomaly in our series was cardiac anomalies (17/58). It is stated that the most frequently observed structural anomaly is cardiac [9, 19]. However, CNS anomalies were most frequently accompanied in another case series [20]. The general recommendation is that omphalocele cases detected in the first trimester and thought to be isolated should definitely be evaluated in the second trimester. Because it may be accompanied by syndromic structural conditions like Pentalogy of Cantrel; bladder exstrophy, imperforate anus, spina bifida complex, Beckwith-Wiedemann syndrome (2). Isolated omphaloceles are related to Beckwith-Wiedemann syndrome with a $10-20 \%$ probability, appropriate prenatal cytogenetic testing should be discussed with patients [7]. The fact that the negative results of molecular genetic tests do not exclude this diagnosis.

This study has some limitations due to its retrospective structure. In addition, the lack of molecular cytogenetic methods is another limitation. But we have a good number of cases for a single center. Follow-up data is also a positive aspect in this study, because newborn care and surgery of cases are performed in the same hospital.

\section{CONCLUSIONS}

In conclusion, it is important to diagnose these cases in the first trimester. Intense efforts should be made to recognize concomitant structural and chromosomal anomalies because they determine the prognosis. If structural and/or chromosomal anomalies are present, the prognosis is poor. Genetic counseling should also be recommended in cases considered to be isolated.

\section{Conflict of interest}

The authors report no conflicts of interest.

\section{REFERENCES}

1. Tassin M, Benachi A. Diagnosis of abdominal wall defects in the first trimester. Curr Opin Obstet Gynecol. 2014; 26(2): 104-109, doi: 10.1097/GCO.0000000000000053, indexed in Pubmed: 24504173.

2. Prefumo F, Izzi C. Fetal abdominal wall defects. Best Pract Res Clin Obstet Gynaecol. 2014; 28(3): 391-402, doi: 10.1016/j.bpobgyn.2013.10.003, indexed in Pubmed: 24342556.

3. Syngelaki A, Chelemen T, Dagklis T, et al. Challenges in the diagnosis of fetal non-chromosomal abnormalities at 11-13 weeks. Prenat Diagn. 2011 ; 31(1): 90-102, doi: 10.1002/pd.2642, indexed in Pubmed: 21210483

4. Fleurke-Rozema $\mathrm{H}$, van de Kamp K, Bakker $\mathrm{M}$, et al. Prevalence, timing of diagnosis and pregnancy outcome of abdominal wall defects after the introduction of a national prenatal screening program. Prenat Diagn. 2017; 37(4): 383-388, doi: 10.1002/pd.5023, indexed in Pubmed: 28219116

5. Syngelaki A, Guerra L, Ceccacci I, et al. Impact of holoprosencephaly, exomphalos, megacystis and increased nuchal translucency on first-trimester screening for chromosomal abnormalities. Ultrasound Obstet Gynecol. 2017; 50(1): 45-48, doi: 10.1002/uog.17286, indexed in Pubmed: 27558969. 
6. Khalil A, Arnaoutoglou C, Pacilli M, et al. Outcome of fetal exomphalos diagnosed at 11-14 weeks of gestation. Ultrasound Obstet Gynecol. 2012; 39(4): 401-406, doi: 10.1002/uog.10048, indexed in Pubmed: 21793081.

7. Schindewolf E, Moldenhauer JS. Genetic counseling for fetal gastrointestinal anomalies. Curr Opin Obstet Gynecol. 2020; 32(2): 134-139, doi: 10.1097/GCO.0000000000000613, indexed in Pubmed: 32039977.

8. Christison-Lagay ER, Kelleher CM, Langer JC. Neonatal abdominal wall defects. Semin Fetal Neonatal Med. 2011; 16(3): 164-172, doi: 10.1016/j. siny.2011.02.003, indexed in Pubmed: 21474399.

9. Gibbin C, Touch S, Broth RE, et al. Abdominal wall defects and congenital heart disease. Ultrasound Obstet Gynecol. 2003; 21(4): 334-337, doi: 10.1002/uog.93, indexed in Pubmed: 12704739.

10. Tassin M, Descriaud C, Elie C, et al. Omphalocele in the first trimester: prediction of perinatal outcome. Prenat Diagn. 2013; 33(5): 497-501, doi: 10.1002/pd.4102, indexed in Pubmed: 23529817.

11. Rossi AC, Prefumo F. Accuracy of ultrasonography at 11-14 weeks of gestation for detection of fetal structural anomalies: a systematic review. Obstet Gynecol. 2013; 122(6): 1160-1167, doi: 10.1097/AOG.0000000000000015, indexed in Pubmed: 24201688.

12. Barisic I, Clementi M, Häusler M, et al. Euroscan Study Group. Evaluation of prenatal ultrasound diagnosis of fetal abdominal wall defects by 19 European registries. Ultrasound Obstet Gynecol. 2001; 18(4): 309-316, doi: 10.1046/j.0960-7692.2001.00534.x, indexed in Pubmed: 11778988.

13. Brantberg A, Blaas HGK, Haugen SE, et al. Characteristics and outcome of 90 cases of fetal omphalocele. Ultrasound Obstet Gynecol. 2005; 26(5): 527-537, doi: 10.1002/uog.1978, indexed in Pubmed: 16184512.

14. Fratelli N, Papageorghiou AT, Bhide A, et al. Outcome of antenatally diagnosed abdominal wall defects. Ultrasound Obstet Gynecol.
2007; 30(3): 266-270, doi: 10.1002/uog.4086, indexed in Pubmed: 17674424.

15. Fleurke-Rozema $\mathrm{H}$, van de Kamp K, Bakker $\mathrm{M}$, et al. Prevalence, timing of diagnosis and pregnancy outcome of abdominal wall defects after the introduction of a national prenatal screening program. Prenat Diagn. 2017; 37(4): 383-388, doi: 10.1002/pd.5023, indexed in Pubmed: 28219116.

16. Syngelaki A, Guerra L, Ceccacci I, et al. Impact of holoprosencephaly, exomphalos, megacystis and increased nuchal translucency on first-trimester screening for chromosomal abnormalities. Ultrasound Obstet Gynecol. 2017; 50(1): 45-48, doi: 10.1002/uog.17286, indexed in Pubmed: 27558969.

17. lacovella $\mathrm{C}$, Contro $\mathrm{E}$, GhiT, et al. The effect of the contents of exomphalos and nuchal translucency at 11-14 weeks on the likelihood of associated chromosomal abnormality. Prenat Diagn. 2012; 32(11): 1066-1070, doi: 10.1002/pd.3959, indexed in Pubmed: 22961234.

18. Hidaka N, Murata M, Yumoto $Y$, et al. Characteristics and perinatal course of prenatally diagnosed fetal abdominal wall defects managed in a tertiary center in Japan. J Obstet Gynaecol Res. 2009; 35(1): 40-47, doi: 10.1111/j.1447-0756.2008.00871.x, indexed in Pubmed: 19215546.

19. Aktoz F, Ozyuncu O, Tanacan A, et al. Gestational Outcomes of Pregnancies with Prenatally Detected Gastroschisis and Omphalocele. Fetal Pediatr Pathol. 2019; 38(4): 282-289, doi: 10.1080/15513815.2019.1585501, indexed in Pubmed: 30892123.

20. Axt R, Quijano F, Boos R, et al. Omphalocele and gastroschisis: prenatal diagnosis and peripartal management. A case analysis of the years 1989-1997 at the Department of Obstetrics and Gynecology, University of Homburg/Saar. Eur J Obstet Gynecol Reprod Biol. 1999; 87(1): 47-54, doi: 10.1016/s0301-2115(99)00078-0, indexed in Pubmed: 10579616. 